\title{
Multiple synostoses syndrome
}

INSERM

\section{Source}

INSERM. (1999). Orphanet: an online rare disease and orphan drug data base. Multiple synostoses syndrome. ORPHA:3237

Multiple synostoses syndrome (MSS) is a rare developmental bone disorder characterized by proximal symphalang ism of the fingers and/or toes often associated with fusion of carpal and tarsal, humeroradial, and cervical spine joints. 